\section{Atmospheric pressure ionisation}

\section{B. Güssregen}

Merck KGaA, Darmstadt, Deutschland
Definition Unter API werden alle massenspektrometrischen Methoden ( $\triangleright$ Massenspektrometrie) zusammengefasst, die Ionen unter Atmosphärendruck erzeugen (z. B. ,electrospray ionisation“ [ESI] und ,atmospheric pressure chemical ionisation“ $[\mathrm{APCI}])$

Synonym(e) API 